
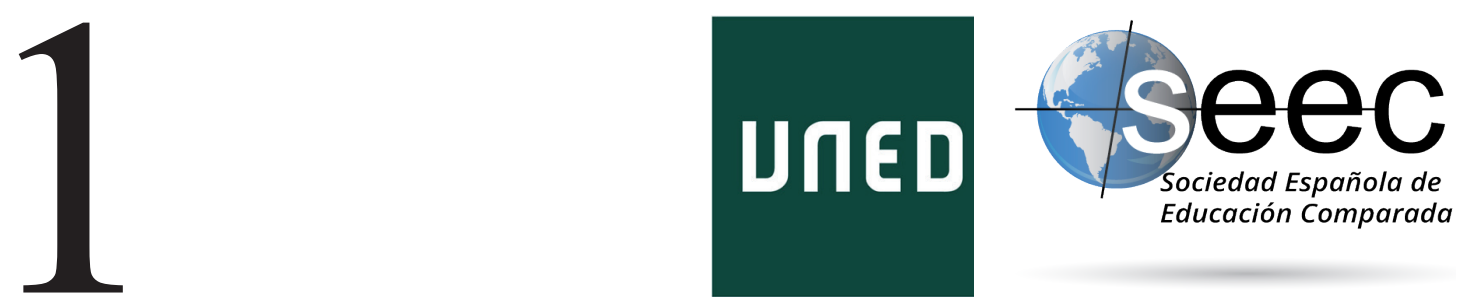

\title{
Editorial: Los retos pendientes de la Estrategia Europea 2020. Una presentación
}

Editorial: The outstanding challenges of the European Strategy 2020. A presentation?

\section{Enric Prats*}

DOI: $10.5944 /$ reec.36.2020.27722

Recibido: 16 de junio de 2020 Aceptado: 16 de junio de 2020

\footnotetext{
* Enric Prats: Profesor de Pedagogía Internacional en la Universidad de Barcelona. Miembro de la coordinación del Programa de Mejora e Innovación de la Formación Inicial de Docentes, del Consejo Interuniversitario de Cataluña. Coordinador editorial de la revista Temps d'Educació. Datos de contacto: E-mail: enricprats@ub.edu
} 
La Estrategia Europa 2020 de Educación y Formación vino a ser, en la década pasada, la esperanza comunitaria para afianzar los resultados más bien modestos de la iniciada en Lisboa en 2000. En marzo de 2010, el Consejo Europeo, celebrado en Bruselas, aprobaba esa nueva estrategia para esta década vencida, en un contexto bien distinto al de 2000, con algunas lecciones aprendidas, pero con las mismas cautelas de Lisboa: dictar objetivos comunes y particulares para cada estado miembro, sin entrar en el desarrollo de políticas precisas. Así, por ejemplo, se plantearían diversos ejes, además de las iniciativas para incentivar la movilidad y el intercambio: en formación profesional, en educación superior y en el desarrollo de competencias clave para la educación básica. Todo ello, en plena puesta en marcha del proceso de Bolonia, que en España empezaba a rodar con las primeras titulaciones de grado y máster justo con el inicio de la década.

En aquel momento, el Consejo Europeo definió cinco objetivos principales para la Unión Europea en 2020, además de objetivos de carácter medioambiental, en materia de clima y energía. Al mismo tiempo, se lanzaban iniciativas en el ámbito de la formación profesional y se reforzaba la educación superior con el desarrollo del Espacio Europeo de Educación Superior y las medidas de reconocimiento mutuo en el ámbito de las cualificaciones profesionales, pero sobre todo se tenía puesta la mirada en lo que vendría a partir de 2020.

En este monográfico de la Revista Española de Educación Comparada se ha ofrecido la posibilidad, a los estudiosos de la Educación Comparada e Internacional, de hacer un balance de esos dos grandes esfuerzos de política educativa supranacional. Como se indicaba en la propuesta de monográfico, se ha pretendido repasar los logros acaecidos en este ámbito, pero también los retos que la experiencia estudiada nos ha aportado. La situación actual ofrece más incertidumbres que certezas, como viene siendo propio de tiempos complejos. A los retos planteados por la salida del Reino Unido de la Unión Europea y la reaparición institucionalizada de populismos en política, más pendientes de las encuestas que de las necesidades de la ciudadanía, se ha sumado una crisis sin precedentes en esta generación como ha sido la emergencia sanitaria global, con unas consecuencias todavía por estudiar.

En este contexto, la escuela emerge, todavía bien entrados ya en el siglo XXI, como un baluarte destacado para el bien de las naciones pero también para entidades de orden supranacional. Esa es la tesis que podría encontrarse también en el desarrollo de un espacio europeo común y en las autoridades comunitarias, que han centrado sus preocupaciones educativas en la necesidad de promover una conciencia ciudadana compartida y de desarrollar unas competencias consideradas clave para vivir en esta Europa que se quiere del conocimiento y la competitividad. La condición de europeísmo ha tenido que lidiar siempre entre los sentimientos nacionales y las aspiraciones supranacionales, una tensión que sustentan Juan Tomás Asenjo y Félix Asenjo en su artículo «Educación y europeísmo, un itinerario de encuentro transnacional.», a modo de freno para el desarrollo de esa deseada dimensión europea por parte de los gobiernos nacionales, atemorizados, sin duda, por perder cuotas de influencia. La formulación en base cuatro, entre identidad, ciudadanía, valores y educación, resulta fundamental para entender la insistencia en promover iniciativas de movilidad que permitan romper la rigidez de las fronteras estatales, como se ha visto con la ampliación de esa movilidad a los centros escolares, volcados a suscribirlas, y en los tímidos pero seguros avances en el desarrollo de las competencias clave, que pueden consolidar esa dimensión europea. 
Esta conciencia compartida de construcción europea viene reforzada cuando encuentra una traducción tácita en términos de progreso colectivo, pero sobre todo en el plano individual; en otras palabras, cuando la ciudadanía admite y reconoce en su práctica diaria los beneficios directos que supone esa dimensión europea. La formación profesional es, sin duda, un segundo pilar fundamental, junto con la escolarización básica en la construcción de Europa. En «Cooperación europea en la formación profesional: hacia una meta común», firmado por Irene Psifidou y Antonio Ranieri, se amplía la tesis de que el desarrollo común está siendo paralelo al afianzamiento de la opción de la formación profesional y vocacional entre la juventud europea. La necesidad de alcanzar altos niveles de cualificación profesional va pareja a la calidad del mercado productivo, un objetivo doble que las autoridades comunitarias se han propuesto en esta década. Las políticas de cooperación desarrolladas en este capítulo, bajo el amparo del Cedefop, han permitido dibujar un marco compartido que refuerza la tríada entre formación, acreditación y empleabilidad, mediante diversos instrumentos creados al efecto. La cooperación analizada en el artículo sería una de las claves en el camino para alcanzar los indicadores fijados, junto con el desarrollo de políticas nacionales sincronizadas con esos objetivos, lo que ha permitido que la formación profesional de alto nivel haya registrado unos niveles de prestigio elevados entre la población europea, según los sondeos expresados en este artículo. Este fenómeno es importante para mejorar los datos económicos y laborales pero resulta crucial para avanzar decididamente en los objetivos colectivos de construcción europea.

En esta consolidación del espacio europeo común, un tercer pilar viene protagonizado por la educación superior y, en particular, por la universidad. En «La Universidad Europea: entre Bolonia y la Agenda 2020", Ernesto Colomo y Francisco Esteban describen la dicotomía que ha vivido históricamente la institución superior en Europa, entre modelos idealistas o humanistas y modelos pragmáticos o progresistas, pareciendo que estos últimos estarían ganado una supuesta batalla de predominio en la formación de los universitarios de nuestro siglo, según los presupuestos del Plan Bolonia. Ciertamente, los datos arrojan un crecimiento importante en los porcentajes de graduados universitarios, especialmente entre las mujeres, en consonancia con el indicador buscado, que en el caso de España se hace más patente en el País Vasco y en Madrid. El dato podría hacer suponer que el modelo pragmático o progresista de universidad está respondiendo a lo que demanda la sociedad, pero puede entreverse que quizás harían falta dosis del modelo humanista para alcanzar con solvencia esa anhelada dimensión europea, en línea con lo que vendrán a plantear los objetivos de sostenibilidad de la próxima década.

En clave local, Carlos Novella firma el artículo que se titula: «¿̨ué pacto educativo necesitamos en España para cumplir con los indicadores del ET 2020?». La tesis del autor, ciertamente controvertida, es que un pacto en el terreno escolar permitiría alcanzar metas elevadas, como las que planteaba la Estrategia 2020. Se puede entender que, en el artículo de Carlos Novella, planea la idea de que ese pacto es la única herramienta para desarrollar políticas eficaces en el terreno educativo, aunque no sea esa directamente su intención. Lo que sí ofrece es un recorrido interesante de carácter histórico sobre las vicisitudes políticas y sociales que han enfrentado a los actores educativos españoles y, en particular, las que han ido paralelas a los vaivenes políticos y legislativos, para comprobar que los objetivos a largo plazo solo pueden conseguirse en sistemas estables. Con las evaluaciones internacionales observando lo que ocurría y los indicadores de la Estrategia 2020 como horizonte, las crisis económicas sucesivas han ido recortando 
progresivamente la posibilidad de llegar a acuerdos, relegando la educación, como la sanidad, a niveles preocupantes. En esta tesitura, las energías gastadas en los intentos de pacto escolar en España han ido chocando con actitudes monolíticas en el terreno político que no favorecían precisamente el consenso, como se constató en la etapa Wert. La condición de estabilidad que se requiere para hacer posible un sistema educativo longevo adquiere toda su fuerza cuando el artículo constata que las disposiciones legislativas de las dos últimas décadas habrían incidido muy levemente en las indicaciones establecidas por las autoridades comunitarias. Para entender esa contradicción, entre la voluntad de someterse a esos indicadores y las políticas erráticas producidas, solo hace falta admitir, como hace el autor, la dificultad que significa aceptar la necesidad de renunciar para alcanzar acuerdos.

Esa misma inquietud debería iluminar la política educativa futura. Partiendo de los principios fundacionales que inspiraron hace siete décadas la cooperación europea, María Matarranz, Javier Valle y Jesús Manso trazan, en su artículo «Después del 2020... Hacia un Espacio Europeo de Educación en 2025», los ejes por los que deberá transitar la consolidación ese espacio educativo compartido. Para ello, hacen un repaso histórico donde se perfilen cuatro grandes momentos, inaugurado con la creación de infraestructuras, pasando por etapas protagonizadas por políticas sectoriales y por políticas globales o integradas, para desembocar en la fase actual de programas estratégicos, donde a su juicio se enmarcaría la Estrategia 2020 de Educación y Formación 2020. El salto cualitativo se produce precisamente a partir de la segunda fase, cuando arrancó la Estrategia de Lisboa, en 2000, momento a partir del cual creció de manera destacada el número de disposiciones vinculantes y no vinculantes emitidas por organismos comunitarios. El horizonte cercano viene dibujado, por lo tanto, por la posibilidad de empezar a constituir ese espacio educativo común en 2025 que se ha ido apuntando en los últimos tiempos por parte de autoridades europeas y del cual todavía se desconocen los detalles.

En definitiva, en las dos últimas décadas, los pasos hacia políticas comunes en lo educativo a escala europea se han ido intensificando y los lazos o compromisos compartidos se han ido estrechando. Como aportan los artículos recogidos en este monográfico, son muchos los logros alcanzados, pero no son menores los nuevos retos que se han ido abriendo. Esta debe ser, con seguridad, una de las características de la educación, un fenómeno vivo y dinámico que requiere una atención cuidada y continuada por parte de todos los actores implicados, especialmente los que tienen más responsabilidad política en ella. 